\title{
Bilingualism, pluralinguism expansion and sociolinguistic analysis in Uzbekistan during the years of independence
}

\author{
Rafiqjon Zaripov Ergashboy ogli \\ "Applied linguistics and linguodidactics" department. \\ doctoral candidate of Alisher Navoi TashSUULL Tashkent. Uzbekistan. \\ E-mail: zaripovrafiqjon1@gmail.com
}

\begin{abstract}
The bilingualism phenomenon has long existed among people living in the territory of Uzbekistan, including Uzbeks, who are able to speak other languages in addition to their native language. Consequently linguistic and extralinguistic influences between the Arabic and Uzbek languages in Central Asia, in VII and VIII centuries it was formed the bilingualism phenomenon in the country. In the XIV-XV centuries, the Persian-Tajik language use in Central Asia expanded and its potential increased. By the XX century, unification of Central Asia to Russian Union, the Russian language influence on the Uzbek language increased. Uzbek-Russian bilingualism formed in Central Asia in parallel with the Uzbek-Arabic and Uzbek-Tajik bilingualism. By this, not only bilingualism, but also pluralinguism had grown significantly among the Uzbek people. Along with linguistic factors, extralinguistic factors also played an important role in Uzbek-Arabic, Uzbek-Tajik and Uzbek-Russian languages development. Within the independence years, the Uzbek language prestige has grown, its scope has expanded. However, some features aforecited languages are preserved in the Uzbek language structure, and these languages units are used in the lexical layer. Our people desire to learn languages is growing, other developed world languages are being studied, and the situation with multilingualism is growing. Similar aspects will be covered throughout the study.
\end{abstract}

Keywords: bilingualism, pluralinguism, linguistic factors, extralinguistic factors, language units, lexical layer.

\section{Introduction}

Bilingualism and multilingualism have existed in our country since ancient times. Due to several nationalities coexistence in our territory, greater part of the population is formed to some extent into several languages. Changes in the country will inevitably affect indigenous people lives. The Uzbek people have long lived in Central Asia and formed as a sedentary people. The Uzbek people have been engaged in agriculture, handicrafts and animal breeding. This activity type was very popular in Central Asia. That's why people prefer to settle down rather than nomadize. The richness, fresh air and other aspects of our country lands have always attracted major colonial powers' attention. Eventually, there were many countries that want to conquer Central Asia. Some large countries, such as hakhans, caliphas and empires, have achieved this goal. As the colonial powers conquered the territories, they tried to assimilate their culture, language, religion, and many other features. It is no exaggeration to say that three colonial powers that colonized Central Asia were able to assimilate their language, religion, and culture while occupying these lands in chronical years terms. These are the Arab Caliphate, the Persian-Tajik countries and the Russian Empire. These colonial states have pursued their own colonial policies in our country and society has changed dramatically. Under these states, the Uzbek nation has survived, despite various abuses. Our nation has not allowed its spiritual, cultural and scientific growth to stop at any time, and has ensured its unique high growth.

\section{Main part}

The greatest Central Asia invaders in chronical years were the Arabs, who tried to conquer our country lands from the VII century, and since then have established their dominance in Central Asia. Eventually, the people life living in the region has changed, and great changes have taken place in their worldview, customs, culture and religious life. Along with Arab Caliphate invasion Islam also entered the Central Asian. Despite the local population domination during the Arab conquest, favorable conditions were created for the science, culture and religion development. The Arabs taught the Arabic language to the colonies people. Consequently significant work in this area, the Arabic language influence in Central Asia increased in the VIII-IX centuries. More and more people are learning it and speaking it. And, there was a biligualism between the Arabic and Turkic languages. Many Arabic lexical units that used in local languages have also increased significantly. It can be said that Arabic was the dominant language - the official state language, the education language, the science and culture language, the fiction, religion and shariah language - which led to Arabic words introduction into Uzbek. Arabic became the dominant language in Central Asia until the XIV-XV centuries. It should be noted that words from nouns and verbs were borrowed from Arabic into Uzbek [2. 20]. Due to the fact that these assimilations have been actively used in our people speech over the years, many lexical units, while serving the Uzbek language enrichment, have become an integral part of our native language and are actively used in conversation. 
Even during independence, Arabic words in the lexical layer of the Uzbek language still make up a large part and are used. Today, the Uzbek language has become a layer in art, literature, people, minister, poet, homeland, state, essay, science, work, education, school, education, secretary, correspondent, spirituality. Arabic words continue to be used actively.

It should be noted that the Arabic words used in the Uzbek language have their own characteristics. In general, most Arabic lexical units show their Arabic features in their usage (see [6. 61]).

Although Uzbek Arabic bilingualism was widespread during the Arab conquest and the next 5 centuries, it later declined for various reasons. During the 150 years before independence, the Arabic language proficiency level among our people fell sharply. After gaining independence, many people interested in the Arabic language in our country has increased, and the mastery rate has increased significantly. As a result, Uzbek-Arabic bilingualism was revived.

Another language that had a great influence on the Uzbek language was Persian-Tajik, which, like Arabic, was widely used in the Uzbek people speech and created the basis for the lexical units' acquisition. It also led to an active Uzbek-Tajik bilingualism formation.

Many linguistic factors played an important role in the Uzbek-Tajik bilingualism emergence. Many linguists have commented on this. In our opinion, the factors mentioned by Professor H. Jamolkhanov are very effective in revealing the Uzbek-Tajik bilingualism (see [1. 191]).

From the above factors, it can be seen that the Uzbek and Tajik peoples have always been side by side, one by one, and have established strong ties in all areas, including in education, culture and enlightenment fields. Together, they have achieved many promising goals, strengthened neighborly relations and lived in harmony. Naturally, as these two nations live in the same area, their cultures and languages interact. This requires intercultural interaction and the bilingualism emergence. Below we consider the languages interaction of these two peoples and the linguistic factors that led to the bilingualism phenomenon.

These languages, in turn, belong to two language groups; Uzbek is one of the Altaic Turkic languages, while Persian-Tajik belongs to the Indo-European language family. Therefore, there are some differences in these languages structure. However, due to the Uzbek and Tajik people coexistence, these two languages influence is obvious, and there are some changes in their linguistic aspects. That is, there is a transition from one language to another, the suffixes addition from one language to another, and bilingualism, diglossy intermingling, and coding in speech.

We can find nouns (barber, avra (front side, top), avra-astar (top lining), feast, leaf, happiness, tree, grove, craft, craftsman), adjectives (stinky, angry, high, equal, burly, exhilarated, giant, fresh, happy, undignified, tidy, clean), adverbs (gladly, suddenly, friendly, quickly, scarcely, sincerely, insomuch), conjunctions (because, or, if, though, also), exclamation (well done, help), particle (well, as), modal verbs (exactly, therefore) are among the Persian-Tajik words in modern Uzbek.

A number of prefixes and suffixes have been learned from Persian-Tajik to Uzbek: prefixes - " $b e$-", " $b a$-", “no-”, “ham-”, “bar-”, “kam-”, “xush-”; suffixes “-kor”, “-zor”, “-xo'r”, “-parvar”, ”-kash”, “-bop”, “-boz”, “do 'z”, "-namo”, “-paz”, “-furush" etc. They were first used in Persian-Tajik words, and later became one of the Uzbek language word-forming affixes, participating in new words formation. There are several word-formation elements in Uzbek that are derived from Tajik and come as a word-formative adverb: as -noma,-obod, -xona, -jon. These morphemes also differ from the Tajik affixes analyzed above in that they can be used as independent lexical units. These suffixes serve as affixes to form Uzbek words. So they are morphemes between affixes and words, affixoids.

We have already considered the Tajik affixes and affixoids functions to form Uzbek words from primitive Turkic words. Uzbek also has many prefixes (prefixes and prefixoids) from Tajik. Some of these suffixes allow to form many Uzbek words from native Turkic words, as well as from assimilated lexical units. They are "ba-, $b o-, b e-, n o-$, ser-" prefixes. There are some opinions in the existing linguistic literature about these prefixes features in new words formation in the Uzbek literary language.

The Uzbek and Turkic languages influence on Tajik language is also very common today. From a sociolinguistic point of view, the Uzbek language influence on the Tajiks speech living in Uzbekistan is obvious, and the Uzbek language linguistic features can be seen in such people speech.

The next major invasion, which led to great changes in Central Asia people's lives, was the Soviet Empire's invasion period and Central Asia conquest. The Soviet state began to occupy Central Asia in the mid-XIX century. Favorable conditions in our country territory made this work even easier, and the Russian state managed to do it. During the Russian occupation, the Russian language prestige increased, and it became an international language. Due to Russification policy, the Russian language has gained a strong position in Central Asia. The Russianspeaking population formation in our country has laid the foundation for Russian-Uzbek bilingualism emergence. In the lexical layer of the Uzbek language, Russian words also appeared. In particular, the use of such words in human speech has increased. In the second half of the XIX century and the beginning the XX century, socio-political changes took place in the lives of Uzbeks. During this period, new shoots of modern industry, science, technology and culture appeared in Uzbekistan. New centers of culture and education have been formed in Central Asia, including Uzbekistan. 
These institutions taught and promoted the advanced scientific and cultural achievements of the time. Since then, Russian has influenced Uzbek. As a result, a number of Russian words began to enter the Uzbek language. Uzbek was introduced into the Russian language and a number of other lexical units from other languages, such as theater, exhibition, car, wagon, railway station, train, artist, samovar, post, electricity.

It should be noted that after the independence of the republic, the scope of the Uzbek language has expanded and the use of lexical units belonging to its strata has increased. However, words learned in Russian and other languages did not lose their activity in the early years of independence. Later, some Russian words began to lose their place. However, words that have been borrowed from Russian and other languages through Russian are still used today.

Words that come to Uzbek not only from Russian, but also from other languages through Russian make up a large part. Such words, which were translated into Russian from other developed languages for various reasons, and which were also introduced into Uzbek as a result of the influence of Russian on the Uzbek language, are still used today. It should be noted that during the years of independence, there have been cases of direct entry of words into Uzbek from a number of developed languages of the world.

We have historically considered the linguistic influence of Arabic, Persian-Tajik, and Russian on Uzbek historically. Below we focus on the extralinguistic factors influencing the above-mentioned languages in the development of the Uzbek language.

Extralinguistic (non-linguistic) factors. These include factors that exist outside of language: forms of social order, historical processes, economic, political, and cultural and enlightenment relations between peoples and nations, the development of science, the development of production and technology, social thinking, the human psyche, emotions, language, and written laws and decrees. For example, after gaining independence, Uzbekistan has undergone significant changes in its socio-political, economic, cultural, educational and spiritual life: the gradual transition to a market economy has begun; the focus on national values has increased., new forms of production and service emerged. All this also affected the lexicon of the Uzbek language: some nouns specific to the state system of the former Soviet Union (words such as party committee, district committee, regional committee, state farm, region) became obsolete, and the Uzbek language became a dictionary. new words and terms (college, lyceum, gymnasium, license, rating, test, marketing, minimarket, investment, business, etc.) required by the life of modern independent Uzbekistan have appeared in their place. In the content of lexical units such as governor, authority, province, district, new aspects of meaning have emerged that are characteristic of the current system, as a result of which such words have passed from the old layer to the modern layer.

It should be noted that the most common and ancient form of bilingualism in Central Asia is formed between the Uzbek and Arabic languages. In the VII century, an Arab caliphate was formed on the territory of the Arab states, which included the Arab tribes. The caliphate became more and more powerful and expanded its territory. As a result, in many parts of the world, along with the Arab people, Arab culture, the Arabic language, and the characteristics of the Arab nations began to take shape among the local population. The establishment of the Arab Caliphate was inextricably linked with the emergence of Islam, and as Islam began to spread among the Arab people, the Arab Caliphate was founded by the alliance of many Arab tribes. As the Arab Caliphate conquered the world, Islam spread to those lands. As a result, the scope of Islam expanded.

In the VII-VIII centuries, Central Asia was colonized by the Arabs. As a result, the Arabs began to dominate Central Asia. By that time, the Arabic language had grown in popularity in the country. Arabic became widely used in law, religion, science, and education. As a result of the political invasion, the people of Central Asia came under the control of the Arabs, and Arab domination on all fronts increased. Indigenous customs, cultures, and religions are slowly changing, and some are disappearing. In particular, the influx of Islam into Central Asia by the Arabs led to the complete substitution of Islam for other religions in the country.

With the arrival of the Arabs in Central Asia, there was a great change in the language. The influence of the local languages declined sharply, and the weight of the Arabic language increased. There were a number of reasons for this including: first of all, one of the main reasons why Arabic became the hegemonic language in Central Asia was that the sources of Islam were in Arabic. In order to learn and master these sources from the original, the locals also had to learn Arabic. Also, during this period, all political, economic, social, cultural and educational, scientific and educational work, all documentation was conducted in Arabic. Such an activity required the mastery of the Arabic language. The Arabs, in turn, pursued a language policy aimed at expanding the scope of the Arabic language. For example, Arabic language textbooks, dictionaries, and Arabic language academies have been established. At the heart of this work was the expansion of the Arabic language, thereby increasing the potential of the Arab state.It should be noted that most of the sources were in Arabic. Acquaintance with Arabic language sources for scientific research in all fields would pave the way for progress in this area. it was also necessary to learn Arabic in order to enter the political process. In short, the importance of the Arabic language in the life of the peoples of Central Asia: the Arab conquest, the spread of Islam, the introduction of the Arabic script, the teaching of Arabic in madrassas, the formation of the Turkic-Arabic bilingualism, the Arabic scholars is inextricably linked to a number of factors, such as the creation of the language. These and other extralinguistic factors, along with the formation of Uzbek-Arabic bilingualism, also affected the structure of the Uzbek 
language and led to a number of linguistic changes.

When thinking about the antiquity of the phenomenon of bilingualism among the Uzbek people, the languages that influenced the Uzbek language and played a special role in the development of the Uzbek language, it is necessary to dwell on the relationship between the Uzbek and Tajik languages. It is permissible. The bilingual population, Uzbek and Tajik, has existed in Movarounnahr since time immemorial. Bilingualism is also reflected in the interaction and cooperation of Persian-Tajik and Old Uzbek literary languages. During the reign of the Samanid dynasty (IX-X centuries) the Persian-Tajik classical literary language began to spread. The Persian-Tajik literary language during this period (VII-VIII centuries) began to displace the Arabic language, which dominated in the field of science and literature, as well as in the field of law. This struggle first led to the Persian-Tajik language squeezing the Arabic language out of poetry in the XI century. In the XIV-XV centuries, Turkic (Uzbek) intellectuals and many poets were fluent in Uzbek and Tajik and were fluent in both languages.

Uzbek-Tajik bilingualism differs from the interaction of Uzbek with other languages in some peculiarities and qualitative features (see [3]).

The Uzbek and Tajik peoples have been living side by side for a long time, living in harmony and kinship with each other. People of Tajik descent can be found in almost all regions of Uzbekistan. In particular, in Samarkand, Bukhara, Surkhandarya, Fergana and other regions, cities and villages. In some areas, they are more numerous. It is possible to observe that the oral speech of the above-mentioned Tajiks living in other places is different. In some places, they speak and communicate entirely in Uzbek. It should be noted that people of Tajik descent can quickly switch from one code to another, depending on the situation. That is, they can speak both Tajik and Uzbek at the same time and have equal access to these languages. They speak Uzbek to Uzbeks and Tajik to Tajiks. However, in some places it is possible to address a Tajik national in Uzbek, as well as an Uzbek national in Tajik. Our observations show that the first case is more pronounced than the second.

Each nation has its own language and culture, and the peoples and nations that live side by side with it grow and prosper together. Because people of different nationalities and ethnic groups live together in the territory of one nation, so they have to influence each other. The cultures, languages, religions, beliefs, lifestyles, customs, and other aspects of the peoples living side by side often become closely intertwined. They are constantly evolving under the influence of each other. However, the ethnicity, language, religion, and beliefs of some of the peoples living side by side are very different. This is particularly the case in areas where Arabs and Jews live. Another example is the sharp differences in the language and religion of the Russian peoples living in the same area as the Turkic peoples, but their way of life and way of life are similar. Their political, economic, cultural and educational development is closely intertwined.

By the end of the XIX century and the beginning of the XX century, the Russian Empire was advancing into Central Asia and gradually began to occupy the territory of the region. He later colonized it and established his rule. After the Soviet Union gained control of Central Asia, it began to pursue its own policy in all areas. Russian rulers also pay close attention to language issues and pursue a policy of russification in the colonized countries. Due to the vastness of the Soviet Union, the colonies were governed by governors-general. They acted in accordance with the laws, decisions and instructions of the center. As in other colonial countries, attention to the language of the peoples of Central Asia declined, and efforts to make Russian the only language of the entire Union flourished. Indigenous languages began to be used only within indigenous peoples. By the early twentieth century, Russian had become the official language of the entire union. Russian language is widely used in politics, economics, science, technology, education, medicine and socio-cultural spheres.

Language policy was based on the unscientific, unnatural, illogical idea that "all languages should become one language in the future." Therefore, the national languages and national cultures of some minorities are not developed at all. As B.R. Karimov and K. Mirazamov wrote: "In the Russian Empire, Russian was declared the state language and a chauvinistic policy was pursued against non-Russian languages ... Due to the theoretical and practical errors in the spirit of chauvinism in the period when the ideology and psychology of stagnation prevailed, the equality and equality of national languages in terms of scope and development was not ensured "[4.3]. The main principle in the language policy of Regal Russia is "centralization, the priority of the Russian language" [5. 43]. That is why measures have been taken in all countries to teach Russian to the population. The Regal administration in Turkestan has taken steps to increase the prestige of the Russian language in Central Asia by teaching the local population Russian. A number of practical works in this direction were carried out in the 80s-90s of the XIX century and the beginning the XX century. Although Russian was declared the official working language in Turkestan by this time, the majority of the indigenous population (including the upper classes) continued to use their mother tongue. Thus, after the Bolshevik revolution in 1917, the situation gradually changed, and on August 30, 1918, the Turkestan ASSR was proclaimed on the territory of the former Governor-General of Turkestan. On August 20, 1918, the Central Social Committee of Turkestan issued a decree. Although the decree was declarative rather than practical, it played a role in the process of approving local languages (including Uzbek) as official languages.These languages have a special place in office work, litigation, public education and other areas.

In 1924, as a result of the delimitation of national statehood, the USSR was formed. Uzbek has been declared 
the state language. A special order has been issued to conduct business in two languages: Russian and Uzbek. In recent years, Uzbek and Russian have been used equally in society. As a result, the structure, lexical layers and other aspects of the Uzbek language have changed. Uzbek-Russian bilingualism has emerged in the country. The status of the Russian language remained influential in the lives of Central Asian nations until the 1990s. The rise of the national liberation movement during this period led to the official status of national languages. This did not affect the status of the Russian language.

There are a number of nations, peoples, tribes and nations in Central Asia that live in friendship and harmony. They are interdependent. During the Soviet era, these peoples were united under the rule of one state, and their language, culture, and spirituality were variously influenced, and the economies of these nations were closely intertwined, bringing the peoples of Central Asia closer together. Nowadays, although they are separate states, these nations are interconnected, because in the territory of one state there are many representatives of other nationalities. As for the territory of Uzbekistan, today about 130 nations and ethnic groups live together in our country.

Every nation wants its language to rise, to have a special place in the world, and to do so. In addition to linguistic factors, extralinguistic factors also have a significant impact on the growth and spread of language. Such factors include the history of the nation and its path, as well as the impact of various changes on the language, economic heights, political changes, the attitude of heads of state to the language, as well as cultural , enlightenment, spiritual uplift.

\section{Conclusion}

From the above, it can be seen that along with linguistic factors, extralinguistic factors also played an important role in the development of Uzbek-Arabic, Uzbek-Tajik and Uzbek-Russian languages. Political, economic, and cultural changes have affected these languages at different times, bringing nation's closer together. Although Uzbek-Arabic bilingualism is not common in our society during the years of independence, bilingualism is widespread among people of Uzbek-Russian and Uzbek-Tajik nationalities. From a sociolinguistic point of view, non-linguistic factors and various changes in society play an important role in the interaction of these languages. One of the most important tasks of our linguistics is to study their development trends in detail.

\section{References}

1. Jamolkhonov J. Modern Uzbek literary language. T.: “Talqin”, 2005. 191 p.

2. Tursunov U, Urinbaev B. History of Uzbek literary language. -Tashkent, 1982. page 20.

3. Begmatov E. Lexical layers of modern Uzbek literary language. - Tashkent.: "Fan" 1985.

4. Karimov B. R., Mira'zamov K. National development and language issues. - T.: 1993. - p. 3.

5. Panassico E.D. Sotsiolinguistic preconditions for the spread of the Russian language and pre-revolutionary Turkestan. - T.: 1989. - S. 43.

6. Turakhujaeva A. From modern Uzbek literary language (lexicology, phraseology, lexicology) (textbook methodical manual) KSPI named after Mukimi - 2006, $61 \mathrm{p}$

7. Mamasaliev, M. M., \& Elboeva, S. B. (2019). RELIGIOUS-PHILOSOPHICAL DOCTRINES OF SARVEPALLI RADHAKRISHNAN. Theoretical \& Applied Science, (11), 339-342.

8. Очилова, Н. Р., Мамасалиев, М. М., \& Астанов, А. Р. (2020). ВНИМАНИЕ ВОСПИТАНИЮ ГАРМОНИЧНО РАЗВИТОГО МОЛОДОГО ПОКОЛЕНИЯ. International Independent Scientific Journal, (14-2), 18-20.

9. Мамасалиев, М. М., \& Бўриев, И. И. (2019). ИНФОРМАЦИОННАЯ БЕЗОПАСНОСТЬ УЧАЩИХСЯОДНО ИЗ ОСНОВНЫХ НАПРАВЛЕНИЙ ДЕЯТЕЛЬНОСТИ ПЕДАГОГА. Іn ФУНДАМЕНТАЛЬНЫЕ ОСНОВЫ ИННОВАЦИОННОГО РАЗВИТИЯ НАУКИ И ОБРАЗОВАНИЯ (pp. 188-190).

10. MATIBAYEVA, R. (2019). THE DEVELOPMENT OF KHANAPHISM IN MAVARANNAKHR. The Light of Islam, 2019(3), 16. 